\title{
Hybrid Imaging in the Assessment of Myocardial Ischemia and Viability
}

\author{
Alexandra Stănescu¹, Diana Opincariu', Nora Rat², Mirabela Morariu1, Sebastian Condrea1, Imre \\ Benedek ${ }^{1,2}$, Theodora Benedek ${ }^{1,2}$ \\ ${ }^{1}$ Center of Advanced Research in Multimodality Cardiac Imaging, Cardio Med Medical Center, Tîrgu Mureș, Romania \\ 2 University of Medicine and Pharmacy, Tîrgu Mureș, Romania
}

\section{CORRESPONDENCE}

\section{Diana Opincariu}

Str. 22 Decembrie 1989 nr. 76

540124 Tîrgu Mureș, Romania

Tel: +40 265217333

E-mail: diana.opincariu@yahoo.ro

\section{ARTICLE HISTORY}

Received: 5 November, 2016

Accepted: 30 November, 2016
Alexandra Stănescu • Str. 22 Decembrie 1989 nr. 76 540124 Tîrgu Mureș, Romania. Tel: +40 265217333. E-mail: alexandrastanescu90@gmail.com

Nora Rat • Str. Gheorghe Marinescu nr. 38, 540139 Tîrgu Mureș, Romania. Tel: +40 265215 551. E-mail: ratnora@gmail.com

Mirabela Morariu • Str. 22 Decembrie 1989 nr. 76 540124 Tîrgu Mures, Romania. Tel: +40 265217333. E-mail: mirabela.morariu@yahoo.com

Sebastian Condrea • Str. 22 Decembrie 1989 nr. 76 540124 Tîrgu Mures, Romania. Tel: +40 265217333. E-mail: sebastian.condrea@yahoo.com

Imre Benedek • Str. Gheorghe Marinescu nr. 38 540139 Tîrgu Mureș, Romania. Tel: +40 265215551. E-mail: imrebenedek@yahoo.com

Theodora Benedek • Str. Gheorghe Marinescu nr. 38 540139 Tîrgu Mures, Romania. Tel: +40 265215551.

E-mail: theodora.benedek@gmail.com

\begin{abstract}
Myocardial ischemia results from a reduction in blood flow as a consequence of a coronary stenosis, which produces ischemia in the myocardial territories irrigated by the stenotic artery. Myocardial viability is a concept that derived from several studies in which it was observed that, even if revascularization occurred, an irreversible left ventricular contractile dysfunction remained. The terms "stunned" and "hibernating" myocardium have been traditionally associated with the viable myocardium, and many controversies still exist on the most appropriate method to assess the presence and extent of viable myocardium. During the last decades, many efforts have been made to identify the best method to determine the viability of the myocardial tissue. Due to the fact that none of the stand-alone imaging methods provide sufficient data about myocardial viability, new methods for the investigation of myocardial viability became necessary. Thus, the concept of hybrid imaging was developed, consisting in the association of different imaging techniques, finally resulting in a single image that offers all the details provided by the two isolated methods of diagnosis, therefore being more precise in regards to the identification of viable myocardium territory. This review aims to appraise the recent studies related to myocardial viability investigated with hybrid imaging.
\end{abstract}

Keywords: myocardial ischemia, hybrid imaging, viability, PET-CT, MRI

\section{INTRODUCTION}

According to World Health Organization (WHO) statistics from 2016, cardiovascular diseases are the principal cause of death worldwide. ${ }^{1}$ Recent research published by Townsend et al. in 2014 highlighted that coronary heart disease (CHD) causes 1.8 million deaths in Europe. ${ }^{2}$ Having such a huge negative impact on the economy and social development, CHD should be diagnosed in early stages. Due to improvements of imagistic diagnostic tools, patients with myocardial ischemia started to have access to superior diagnostic techniques, resulting in a better therapeutic approach. Nichols et al. showed in an epidemiological update regarding cardiovascular disease mortality, that there is a descending trend in mortality caused by CHD in almost all European countries. ${ }^{3}$ 
Myocardial ischemia represents a condition that occurs when aerobic metabolism changes into an anaerobic one. This can represent the first sign before the occurence of an acute myocardial infarction. The underlying pathogenetic mechanism involved in the progression of myocardial ischemia is the development of atherosclerosis, leading to coronary stenosis and a decreased blood supply in the affected territories, which finally causes contractile impairment. Myocardial ischemia can be diagnosed using several imaging methods, such as echocardiography with contrast enhancement or with dobutamine, conventional coronary angiography, computed tomography angiography, magnetic resonance imaging and nuclear imaging.

Myocardial viability is a term characterizing the myocardial tissue, without scars or with limited ones, which suffered from severe ischemia that produced significant contractility impairment, but has the possibility to recover its functional status after the blood flow is reestablished. ${ }^{4}$ Several studies have investigated this concept, thus updating the approach of patients with myocardial infarction. In 2006, Tarakij et al., in a study on 765 patients with severe impairment of left ventricular (LV) function, showed that patients who underwent early revascularization therapies (percutaneous coronary intervention - PCI or coronary artery bypass grafting - CABG) for extensive $\mathrm{CAD}$, had significantly lower mortality rates during the 3-year follow-up. ${ }^{5}$

Moreover, clinicians should consider the assessment of myocardial viability for a better approach of CAD patients that can aid in the examination and establishing the indication of coronary revascularization. In the assessment of myocardial viability, positron emission tomography (PET) is considered the gold standard method for evaluating functional recovery after revascularization. ${ }^{6}$

\section{MYOCARDIAL STUNNING AND HIBERNATION}

The term "myocardial stunning" describes a viable myocardial tissue with contractile dysfunction following a severe abrupt ischemic injury, which recovers its function spontaneously, without the need for coronary revascularization. ${ }^{7}$ Myocardial stunning results after repeated episodes of reversible myocardial ischemia associated with angina pectoris with or without ECG changes, after which the myocardial tissue remains non-functional in terms of contractility, but with normal blood flow.

Hibernating myocardium represents a different type of viable myocardium, which recovers its contractile function after a successful revascularization. In opposition with myocardial stunning, a hibernating myocardium requires an intervention to improve its function, either through pharmacological therapy or by coronary revascularization. It is important to differentiate between a hibernating and an irreversible ischemic myocardium. The first one will recover after revascularization, and the patient with hibernating myocardium will benefit from the coronary intervention, which will lead to a significant improvement in left ventricular function. ${ }^{8}$

\section{COMPUTED TOMOGRAPHY ANGIOGRAPHY IN THE ASSESSMENT OF MYOCARDIAL VIABILITY AND ISCHEMIA}

Being more widely available and more often used due to lower costs, delayed contrast-enhancement multi-slice spiral computed tomography (MSCT) can assess myocardial viability, providing information about the anatomy of the coronary vessels, together with details on their functionality. ${ }^{9}$

The main limitation of this technique comes from the radiation exposure that must be taken into consideration. One of the features that characterize an infarcted territory, as seen in cardiac MSCT, is low contrast enhancement after the arterial phase, which shows a deficient coronary perfusion. Yamauch et al. showed the benefits of using perfusion computed tomography angiography in the assessment of the myocardial ischemia in stable patients. They performed a study on 2,878 symptomatic patients with suspected coronary artery disease and concluded that the patients who underwent perfusion computed tomography angiography had a better prognosis compared with those who underwent direct percutaneous coronary intervention. ${ }^{10}$

In an attempt to assess the accuracy of MSCT for the assessment of myocardial ischemia and viability, many studies found that MSCT has a sensitivity of $95-97 \%$ and a specificity of $93-98 \%$ in detecting the coronary artery stenosis associated with myocardial ischemia. An important limitation of this noninvasive diagnostic procedure is that in case of lesions with a high degree of calcification, the stenosis can be overestimated. ${ }^{11-14}$

Albert et al. studied the accuracy of MSCT in detecting myocardial necrosis and viability after myocardial infarction in 10 dogs and 7 pigs. They produced a myocardial infarction by performing a balloon occlusion in one of the coronary arteries, which was followed by percutaneous revascularization. Their results showed that myocardial ischemia and the extension of the myocardial infarction can be accurately analyzed by MSCT, leading to a precise diagnosis. ${ }^{15}$ 
By combining the images obtained via CT (that offer data on the anatomy of the coronary tree) with PET image acquisitions (that indicate the functionality of the myocardial tissue), the resulted fusion images can improve the decision-making process on the need for revascularization.

\section{MAGNETIC RESONANCE IMAGING (MRI) DISTINGUISHES VIABLE MYOCARDIUM FROM INFARCTED MYOCARDIAL TISSUE}

MRI is a valuable diagnostic tool in the assessment of myocardial injuries. Being a noninvasive method without many limitations, it can differentiate the viable myocardium from scar tissue. Therefore, it represents an important imaging technique that leads to an accurate diagnosis. ${ }^{16}$ Furthermore, MRI can help in investigating the need of coronary revascularization in ischemic territories, and to predict whether the restoration of the blood flow will lead to functional recovery of the affected myocardial tissue. Currently, there are three techniques used for the assessment of myocardial viability and ischemia based on magnetic resonance: resting MRI, dobutamine MRI and contrast-enhanced MRI. In a report, Schinkel et al. stated that a myocardium with a measured thickness of less than $6 \mathrm{~mm}$ indicates a scar tissue that will probably not recover after the restoration of blood supply in the afferent territory. That means that the myocardial wall thickness assessed by MRI can be a predictive factor for the outcome of patients following a myocardial infarction. ${ }^{6}$

Wellnhofer $e t$ al. conducted a prospective blind study on 29 patients with coronary artery disease, in which they assessed myocardial viability and the functional recovery after revascularization by performing dobutamine-MRI and contrast-enhanced MRI. They found that low-dose dobutamine MRI has a better predictive capacity for myocardial recovery compared to contrast-enhanced MRI and is not dependent on the depth of the scar. Similar results were obtained by Motoyasu et al. in their research. ${ }^{17,18}$ Contrariwise, Van Hoe et al. did not find any advantages for stress MRI over contrast-enhanced MRI in the assessment of viable myocardium, and they stated that the dobutamine stress test associated with MRI should not be integrated in the protocol for the evaluation of myocardial viability, as it offers no additional information. ${ }^{19}$

Klein et al. compared contrast enhancement MRI with PET in 31 patients with known CAD and showed that MRI hyperenhancement can better assess the scar tissue in comparison with PET, which is considered the best method in evaluating myocardial viability and can be a good predictor for functional recovery. ${ }^{20}$

\section{STRESS ECHOCARDIOGRAPHY USED FOR EVALUATING THE VIABLE MYOCARDIUM}

Using echocardiography with the administration of dobutamine, the contractile reserve of the myocardial tissue can be determined, thus enabling the evaluation of the functional recovery of the myocardium after revascularization. Low-dose dobutamine infusion associated with ultrasound can identify the viable myocardium with contractile dysfunction and can reveal myocardial ischemia by increasing the dose of dobutamine, leading to an increased need for oxygen. ${ }^{21}$

This method is limited due to the fact that it requires an experimented operator, thus being preferred to be used in association with other imaging techniques. Wang et al. combined in their myocardial viability study the lowdose dobutamine echocardiography with speckle-tracking echocardiography and with delayed enhancement MRI in 35 patients who had previously suffered an acute myocardial infarction. They observed that by using this association, the sensitivity and specificity in detecting the viable myocardium was increased considerably, but due to the small size of the study sample, their results were not representative. ${ }^{22}$

\section{NUCLEAR IMAGING FOR MYOCARDIAL ISCHEMIA AND VIABILITY ASSESSMENT}

PET-FDG has an increased value in the evaluation of myocardial viability, ${ }^{23}$ with a $92 \%$ sensitivity in evaluating myocardial viability. ${ }^{6}$ Even if it has a high diagnostic value, it is not frequently used due to its increased costs and reduced availability.

\section{HYBRID IMAGING FOR THE ASSESSMENT OF MYOCARDIAL VIABILITY}

Hybrid imaging represents the association of two different imaging technologies into a single examination, which is able to provide all the details that would be obtained separately by each of the two techniques, in a single step. Examples of hybrid imagistic methods are: MRI/PET, PET/ CT, MR/SPECT, ultrasound/MR, or ultrasound/CT. The advantages of using such models are related to the high diagnostic accuracy and the reduced exposure to radiations. This new imaging technology represents an upgrade in the diagnostic precision of myocardial ischemia by providing more information in regards to the possibility of coronary revascularization and the functional recovery of the myocardial tissue after restoring the blood flow. 
Masuda et al. recently published a study on 12 patients, in which they assessed myocardial viability using a new technique consisting of the integration of two different imaging methods: cardiac MRI and PET. They found a positive correlation between cardiac wall thickness and fluorodeoxyglucose (FDG) uptake with the patients' outcome. ${ }^{24}$

Hybrid imaging accomplished by the association of CT and MRI with PET can be used for the assessment of the extension of viable myocardium after acute coronary syndromes. The result provided by this kind of hybrid imaging is a single scan and a single fusion image that allows the clinician to evaluate the morphology and functionality of the myocardial tissue, being a valuable predictor for functional recovery after revascularization in patients with previous myocardial infarction. This hybrid method can also be used for the examination of patients with sarcoidosis, with reduced left ventricular ejection fraction or other cardiomyopathies. ${ }^{25,26}$

Hybrid imaging tools may improve the outcome of coronary patients by evaluating cardiovascular risks, and they can also decrease the costs of further investigations. The technique can be used for the identification of patients with viable myocardium, as established with the use of noninvasive imaging tools. This is particularly important because these patients will truly benefit from revascularization and should undergo percutaneous coronary intervention. . $^{2728}$

\section{CONCLUSIONS}

Hybrid imaging represents the future of imaging methods in investigating myocardial ischemia and viability. Further research is required to illustrate the real advantages of these techniques in providing more complex information for the selection of patients who will truly benefit from revascularization procedures.

\section{CONFLICT OF INTEREST}

Nothing to declare.

\section{ACKNOWLEDGEMENT}

This research was supported via the research grant no. 103545/2016, contract number 43/05.09.2016, entitled "High performance multimodal MRI/CT imaging platform, for applications in computational medicine, nanoparticles and hybrid imaging for the research of atherothrombotic disorders - CARDIO IMAGE" financed by the Romanian Ministry of European Funds, the Romanian Government and the European Union.

\section{REFERENCES}

1. World Health Organization, Cardiovascular disease (CVDs), 2016 Available from: http://www.who.int/mediacentre/factsheets/fs317/en/\#

2. Townsend N, Nichols M, Scarborough P, Rayner M. Cardiovascular disease in Europe - epidemiological update 2015. Eur Heart J. 2015;36:2673-2674.

3. Nichols M, Townsend N, Scarborough P, Rayner M. Cardiovascular disease in Europe 2014: epidemiological update. Eur Heart J. 2014;35:2950-2959.

4. Camici PG, Prasad SK, Rimoldi OE. Stunning, hibernation, and assessment of myocardial viability. Circulation. 2008;117:103-114.

5. Tarakji KG, Brunken R, McCarthy PM, et al. Myocardial viability testing and the effect of early intervention in patients with advanced left ventricular systolic dysfunction. Circulation. 2006;113:230-237.

6. Schinkel AF, Bax JJ, Poldermans D, Elhendy A, Ferrari R, Rahimtoola SH. Hibernating myocardium: diagnosis and patient outcomes. Curr Prob/ Cardiol. 2007;32:375-410.

7. Brauwald E, Kloner RA. The stunned myocardium: prolonged, postischemic ventricular dysfunction. Circulation. 1982;66:1146-1149.

8. Cleland JG, Pennell DJ, Ray SG, et al. Myocardial viability as a determinant of the ejection fraction response to carvedilol in patients with heart failure (CHRISTMAS trial): randomised controlled trial. Lancet. 2003;362:14-21.

9. Partington SL, Kwong RY, Dorbala S. Multimodality imaging in the assessment of myocardial viability. Heart Failure Reviews. 2011;16:381-395.

10. Yamauchi T, Tamaki N, Kasanuki H, et al. Optimal initial diagnostic strategies for the evaluation of stable angina patients: a multicenter, prospective study on myocardial perfusion imaging, computed tomographic angiography, and coronary angiography. Circ J. 2012;76:2832-2839.

11. Nikolaou K, Knez A, Rist C, et al. Accuracy of 64-MDCT in the diagnosis of ischemic heart disease. Am J Roentgenol. 2006;187:111-117.

12. Ehara M, Surmely JF, Kawai M, et al. Diagnostic accuracy of 64-slice computed tomography for detecting angiographically significant coronary artery stenosis in an unselected consecutive patient population: comparison with conventional invasive angiography. Circ J. 2006;70:564-571.

13. Ropers D, Pohle FK, Kuettner A, et al. Diagnostic accuracy of noninvasive coronary angiography in patients after bypass surgery using 64-slice spiral computed tomography with 330-ms gantry rotation. Circulation. 2006;114:2334-2341.

14. Raff GL, Gallagher MJ, O'Neill WW, Goldstein JA. Diagnostic accuracy of noninvasive coronary angiography using 64-slice spiral computed tomography. J Am Coll Cardiol. 2005;46:552-557.

15. Lardo AC, Cordeiro MA, Silva C, et al. Contrast-enhanced multidetector computed tomography viability imaging after myocardial infarction characterization of myocyte death, microvascular obstruction, and chronic scar. Circulation. 2006; 24;113:394-404

16. Bax JJ, Delgado V. Myocardial viability as integral part of the diagnostic and therapeutic approach to ischemic heart failure. J Nucl Cardiol. 2015;22:229-245

17. Wellnhofer E, Olariu A, Klein C, et al. Magnetic resonance low-dose dobutamine test is superior to SCAR quantification for the prediction of functional recovery. Circulation. 2004;109:18:2172-2174.

18. Motoyasu M, Sakuma H, Ichikawa $Y$, et al. Prediction of regional functional recovery after acute myocardial infarction with low dose dobutamine stress cine MR imaging and contrast enhanced MR imaging. J Cardiovasc Magn Reson. 2003;5:563-574.

19. Van Hoe L, Vanderheyden M. Ischemic cardiomyopathy: value of different MRI techniques for prediction of functional recovery after revascularization. Am J Roentgenol. 2004;182:95-100.

20. Klein C, Nekolla SG, Bengel FM, et al. Assessment of myocardial viability with contrast-enhanced magnetic resonance imaging comparison with positron emission tomography. Circulation. 2002;105:162-167.

21. Li Dy, Hao J, Xia Y, et al. Clinical usefulness of low-dose dobutamine stress real-time myocardial contrast echocardiography for detection of viable myocardium. J Clin Ultrasound. 2012;40:272-279.

22. Wang C, Han S, Xu T, et al. Evaluation of myocardial viability in old myocardial infarcted patients with $\mathrm{CHF}$ : delayed enhancement MRI vs. low-dose dobutamine stress speckle tracking echocardiography. American Journal of Translational Research. 2016;8:3731-3743.

23. Al Moudi M, Sun Z-H. Diagnostic value of $18 F-F D G$ PET in the assessment of myocardial viability in coronary artery disease: A comparative study with 99mTc SPECT and echocardiography. Journal of Geriatric Cardiology. 2014;11:229-236.

24. Masuda A, Yamaki T, Kunii H, et al. Simultaneous Assessment of Myocardial Viability With 18F-fluorodeoxyglucose Uptake and Late Gadolinium Enhancement by PET/MRI. Circulation. 2016;134:A11929 
25. Danad I, Raijmakers PG, Appelman YE, et al. Hybrid imaging using quantitative H2 150 PET and CT-based coronary angiography for the detection of coronary artery disease. J Nucl Med. 2013;54:55-63.

26. Kajander S, Joutsiniemi E, Saraste M, et al. Cardiac positron emission tomography/computed tomography imaging accurately detects anatomically and functionally significant coronary artery disease. Circulation. 2010;122:603-613.
27. Schenker MP, Dorbala S, Hong EC, et al. Interrelation of Coronary Calcification, Myocardial Ischemia, and Outcomes in Patients With Intermediate Likelihood of Coronary Artery Disease A Combined Positron Emission Tomography/Computed Tomography Study. Circulation. 2008;117:1693-1700

28. Kaufmann PA. Cardiac hybrid imaging: state-of-the-art. Ann Nucl Med 2009:23:325-331. 